
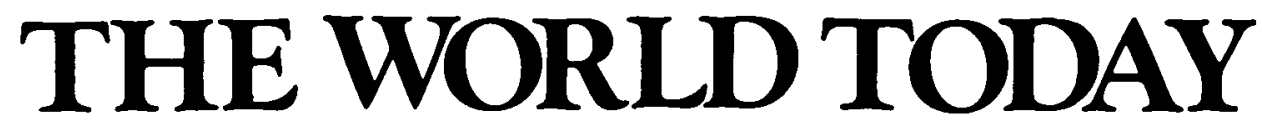

STUDENTS OF CURRENT AFFAIRS, to be well informed, need the facts. In THE WORLD TODAY, the monthly journal of the Royal Institute of International Affairs, experts bring to the general reader up-to-date and reliable information on world affairs.

Authoritative and objective, THE WORLD TODAY deals primarily with international problems but also includes articles on internal political and economic conditions in individual countries or regions, written by authors with first-hand knowledge. Short comment in 'Notes of the Month' puts current developments into perspective and provides a background to events of international significance.

Annual subscription (12 issues a year including postage inland and overseas) Vol. $38 \quad 1982$

USA

$\$ 34$

UK

$£ 12$

Elsewhere

$£ 15$

Published under the auspices of the

\title{
ROYAL INSTITUTE OF INTERNATIONAL AFFAIRS LONDON
}

by the Oxford University Press

Walton Street, Oxford OX2 6DP 


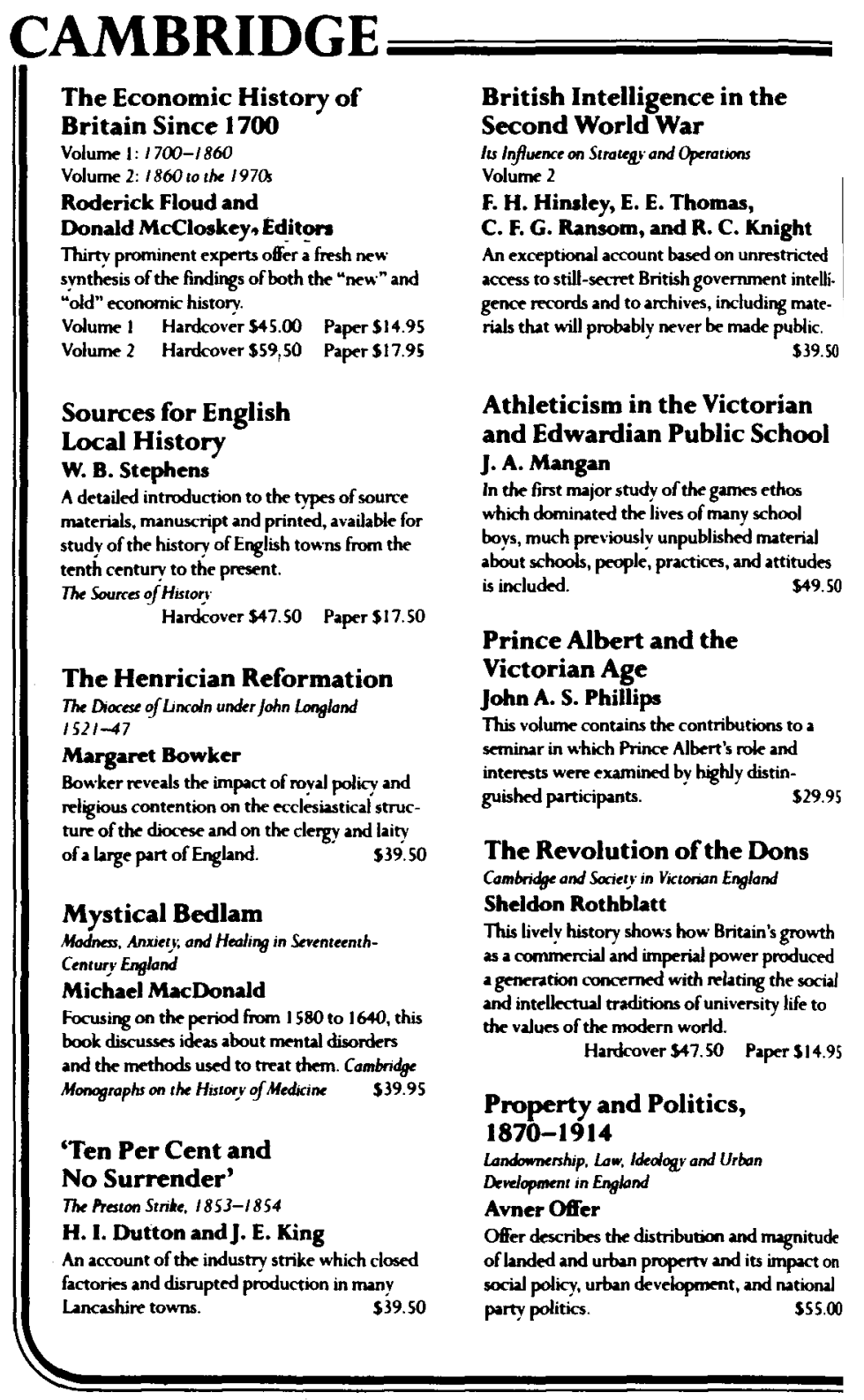




\section{The Culture of Consent}

Mass Orgonization of Leisure in Fascist Itoly Victoria de Graxia

Professor de Grazia's study of the dopolavorothe organization that sought to organize mass culture in the service of the government examines its history, major spheres of activity, the methods it used, and its implications for Italian fascism.

\section{Another Dimension to the Black Diaspora \\ Diet, Disease, and Racism}

Kenneth F. Kiple and

Virginia Himmelsteib King

A controversial analysis of the history of black diseases and medical practices. It establishes a link between differences in black and white disease patterns and American racism. \$29.95

\section{Heart-Beguiling Araby Kathryn Tidrick}

This portrayal of British travelers and explorers among the Arabs concentrates on individuals from Sir Richard Burton to T. E. Lawrence, and shows how the stereotype of the desert Arab as dishonest was gradually replaced by the ideal of the noble Bedouin.

\section{The Mandarin-Capitalists} from Nanyang

Overseas Chinese Enterprise in the Modernisation of Chino 1892-1911

\section{Michael R. Godley}

Godley considers the political and commercial influence of the overseas Chinese and the modernisation of China. Combridge Studies in Chinese History, Literature and Institutions

$\$ 39.50$

\section{Organised Workers and Socialist Politics in Interwar Japan Stephen S. Large} A groundbreaking examination of the Japanese socialist movement from the perspective of the organized workers who have pmovided the socialist parties with much of their support.

\section{Capitalism and the State in Modern France}

Renovation and Economic Management in the Twentieth Century

\section{Richard F. Kuisel}

"Kuisel's work will be received as the most important book on French history since Stanley Hoffman's In Search of Fronce. And the significance of Kuisel's work goes beyond French history, since it deals with the changing nature of capitalism and shows how such changes can be expressed in historical terms." $\rightarrow$ Martin Wolfe, University of Pennsylvania

Interpreting the

French Revolution

M. Francois Furet

Elborg Forster, Translator

One of France's most distinguished historians offers a significantly different interpretation of the Revolution, identifying radical changes it produced as well as the continuity it provided. Handcover $\$ 29.95$ Paper $\$ 9.95$

\section{The Enlightenment in}

\section{National Context}

Roy Porter and Mikulax Teich,

\section{Editors}

This book not only shows the regional differences in the Enlightment, but also how central concerns were shared everywhere. Hardcover \$39.50 Paper \$14.95

\section{The Rites of Rulers}

Aitual in Industrial Saciety: The Soriet Case Christel Lane

Dr. Lane gives a detailed account of the major Soviet rites and an analysis of the role of ritual in the USSR. Handcover \$47.50 Paper \$14.95

\section{Early Muslim Dogma}

A Source-Critical Study

Michael Cook

A new source for the early history of the Murji'a is presented, and a new position is argued regarding the early doctrine and politics of the movernemt. $\quad \$ 49.50$

\footnotetext{
all proses subpect to shange
} 


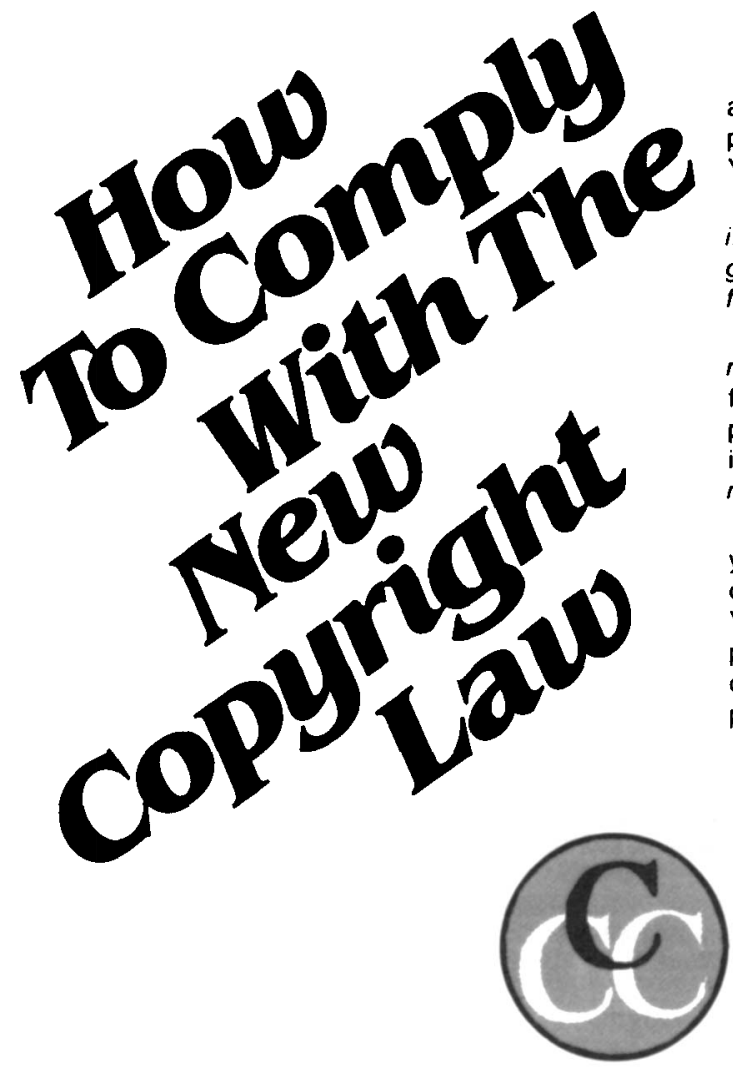

Participation in the Copyright Clearance Center ( $\mathrm{CCC}$ ) assures you of legal photocopying at the moment of need. You can:

Fill requests for multiple copies, interlibrary loan (beyond the CONTU guidelines), and reserve desk without fear of copyright infringement.

Supply copies simply and easily from registered publications. The CCC's flexible reporting system accepts photocopying reports and returns an itemized invoice. You need not keep any records, our computer will do it for you.

The Copyright Clearance Center is your one-stop place for on-the-spot clearance to photocopy for internal use. You will never have to decline a photocopy request or wonder about compliance with the law for any publication registered with the CCC.

For more information, just contact:

\section{Copyright}

\section{Clearance Center}

21 Congress Street

Salem, Massachusetts 01970

(617) 744-3350

a not-for-profit corporation 
Comparative Studies in Society and History is a forum for presentation and discussion of new research into problems of change and stability that recur in human societies through time or in the contemporary world. It sets up a working alliance between specialists in all branches of the social sciences and humanities. Debate and review articles bring the general reader in touch with current findings and issues.

\section{NOTES FOR CONTRIBUTORS}

Contributions may be descriptive, analytical or theoretical. Any article not in itself comparative may be accepted if it lends itself to comment that will place it in comparative perspective. Correspondence with the editors prior to the submission of articles will help to enable them to obtain such comment or a companion study. Emphasis in comparative studies may be either on similarities or, if these are significant enough and call for some recasting of generalizations, on differences. All contributions and editorial correspondence should be sent to the Editors, Comparative Studies in Society and History, Department of History, University of Michigan, Ann Arbor, Michigan 48109.

Two copies of each contribution, preferably accompanied by a stamped, addressed envelope, should be submitted. Both text and footnotes should be clearly typed with double spacing and wide margins; footnotes should appear on separate pages at the end of the article. Illustrations may be included by arrangement with the editors.

Contributors will receive 50 offprints. Any additional offprints must be ordered on receipt of the first proof. 


\section{COMPARATIVE STUDIES IN SOCIETY AND HISTORY}

Editorial Foreword

Politics and Religion

Allan Christelow The Muslim Judge and Municipal

Politics in Colonial Algeria and Senegal

Günter Golde Voting Patterns, Social Context, and Religious Affiliation in Southwest Germany

Household Structure

Roger Sanjek The Organization of Households in Adabraka: Toward a Wider Comparative Perspective

Roderick J. Lawrence Domestic Space and Society: A Cross-Cultural Study

The Human Nature of Materialism

J. S. Otto and N. E. Anderson Slash-and-Burn Cultivation in the Highlands South: A Problem in Comparative Agricultural History

ErIC R. Wolf Materialists vs. Mentalists. A Review Article

Robert I. Burns, S. J. Relic Vendors, Barefoot Friars, and Spanish Muslims: Reflections on Medieval Economic and Religious History. A Review Article

Jerrold Seigel Consciousness and Practice in the History of Marxism. A Review Article

\section{Cambridge University Press}

The Pitt Building, Trumpington Street, Cambridge CB2 IRP

32 East 57 Street, New York, N.Y. 10022

296 Beaconsfield Parade, Middle Park, Melbourne 2306

(C) 1982 Society for the Comparative Study of Society and History

Printed in the United States of America 